\title{
AVALIAÇÃO DE RESULTADOS DA CAPACITAÇÃO DOCENTE: O PÓS-DOUTORADO NA UNIVERSIDADE FEDERAL FLUMINENSE SOB A ÓTICA DA PRODUÇÃO CIENTÍFICA E BIBLIOGRÁFICA
}

\author{
Marcello Vinicius Doria Calvosa* \\ Melina Garcia Repossi** \\ Pedro Marcos Roma de Castro***
}

Recebido: maio 2010

Aprovado: nov. 2010

\begin{abstract}
*Doutorando FEA-USP e Prof. Efetivo DCAC/UFRRJ. E-mail: mvcalvosa@usp.br
** Graduanda de Administração de Empresas - UFRRJ. E-mail: melinarepossi@hotmail.com

*** Doutorando em Administração FEA-USP, Analista em Ciência e Tecnologia CAPES. E-mail: pedro. castro@capes.gov.br
\end{abstract}

Resumo: A pesquisa aqui apresentada teve como objetivo investigar a influência do estágio pós-doutoral sobre a produção científica e bibliográfica de pesquisadores/docentes atuantes em programas de pós-graduação da Universidade Federal Fluminense - UFF. Estudos sobre o fenômeno pósdoutoral são escassos na literatura e os poucos trabalhos encontrados na literatura internacional versam apenas sobre a realidade de uma única Instituição de Ensino Superior. O estudo busca a mensuração de variações da produção docente registrada em periódicos científicos em um panorama ex-ante e ex-post e busca ampliar o escopo dos estudos dessa área de investigação para abranger também a realidade de uma universidade federal. Com uma população de 278 doutores que realizaram o estágio pós-doutoral até 2008 , os dados levantados apontam para um aumento expressivo da UFF na realização dos estágios pós-doutorais, especialmente, nos últimos dez anos, demonstrando o perfil institucional dos docentes que privilegiam e publicam maciçamente em anais de eventos, e como resultado mais relevante que a demanda ou oferta pela realização de estágios pós-doutorais é homogênea entre os diversos estratos da carreira docente, tendo os mesmos níveis percentuais entre docentes recém-doutores e seniores. Quando o foco é o desempenho, nesse caso específico a produtividade em pesquisa, as evidências demonstraram que docentes de pós-graduação na UFF, em geral, beneficiam-se da realidade pós-doutoral, em especial os docentes com maior tempo de conclusão do doutorado. Eles buscam, por meio da socialização, uma oportunidade de atualização e reciclagem de conhecimentos por intermédio da interação com um conhecimento gerado. No caso do pós-doutorado, isso ocorre por conectividade com outras universidades ou grupos de pesquisa.

Palavras chave: Pós-doutorado. Produção científica. Gestão do conhecimento. Perfil docente.

\section{EVALUATION RESULTS OF THE TEACHER TRAINING PROGRAM: THE POST- DOCTORATE AT THE UNIVERSIDADE FEDERAL FLUMINENSE FROM THE SCIENTIFIC PRODUCTION AND BIBLIOGRAPHIC VIEWPOINTS}

Abstract: The following research had the objective of investigating the influence of the post-doctoral training program on the scientific and bibliographic literatures produced for researchers/professors 
involved in graduate programs at Universidade Federal Fluminense - UFF. Studies about the post-doctoral phenomenon are rare in literature and the few studies found in international literature only refer to the reality of a single Higher Education Institute. This paper intends to measure the changes in the professors' production registered in scientific journals under the perspectives ex-ante and ex-post, also looking to expand the scope of studies of this field of research and embracing the reality of a federal university. With a population of 278 doctors who performed their post-doctorate studies until 2008 , the results point to a significant increase of the UFF postdoctoral training program, especially in the last ten years, evidencing the institutional profile of the professors who honor and publish massively in conferences. The most relevant result is that this university is homogeneous among the various teaching profession strata in its demand or supply for post-doctoral placements, having the same percentage levels among new professors and senior professors. When the performance is the focus, that is, the productivity in research, the evidences showed that the post-graduate professors at UFF, in general, take advantage of the post-doctoral reality, especially the older ones in doctoral completion. They seek, through socialization, an opportunity to update and recycle the knowledge through interaction with a recently generated knowledge. Regarding the post-doctorate this happens by connectivity with other universities or research groups.

Key words: Post-doctorate. Scientific Production. Management of Knowledge. Professors' Profile.

\section{INTRODUÇÃO}

A visão nesse artigo é que a capacitação via estágio pós-doutoral age como peça recente na engrenagem da pesquisa, não essencial, mas sim opcional para a carreira acadêmica, mas que, no entanto, ganha grande destaque nos últimos anos, dentre outros aspectos, dada a sua relevância para o conhecimento, o aprimoramento de competências, a reciclagem profissional e de forma geral a necessidade de atualização. Esta ideia está presente e fortemente alicerçada em dados empíricos, em trabalho constante nos anais do último EnANPAD (CASTRO; PORTO; KANNEBLEY JR, 2009).

Fora do âmbito dos EnANPADs, pesquisou-se a literatura científica publicada em periódicos nacionais e internacionais, utilizando as palavras-chaves: postdoctoral research, sabbatical stay, postdoctoral stage, post doctorate, postdoctoral training, capacitación postdoctorales, etapa de post-doctorado, post-doctorado, pós-doutorado, estágio pós-doutoral e treinamento pósdoutoral. Surpreende a tamanha escassez de trabalhos sobre um assunto, em princípio, tão relevante, seja: para a academia, para a gestão e fomento, para os aspectos da carreira docente, da capacitação e formação do pesquisador e para as políticas públicas de maneira mais ampla.

Inicialmente procurou-se pelo termo chave postdoctoral research, comumente utilizado para denominar os estágios pós-doutorais em países de língua inglesa. No entanto, o termo não resgatava nenhum artigo sobre o tema que te- 
nha sido publicado nos principais periódicos; como citado, ampliou-se então, a variabilidade dos termos chaves, e, também, a base de dados com consultas no: Web of Science, Pro Quest, Scielo e portal periódicos da CAPES. Nenhum artigo sobre o tema foi encontrado.

Além deste método, houve a consulta em sites específicos das revistas classificadas na base Qualis como B3 ou superior. Foi, então, localizado e/ou encontrado um $^{(1)}$ artigo que versa sobre o tema (CASTRO; PORTO, 2008), publicado na Organizações e Sociedade, revista nacional da área de administração e atualmente classificada como B2.

Nesse cenário, parece que os autores constituem-se pioneiros, abrindo com mérito um espaço pouco explorado em pesquisa; no entanto, cabe frisar, que todo o trabalho volta-se exclusivamente para a realidade pós-doutoral das hard sciences da Universidade de São Paulo - USP.

O balanço é que a conjuntura atual impulsiona a valorização dos programas de capacitação por meio do aperfeiçoamento em pesquisa via estágios de pós-doutoramento, mas por outro lado, a academia que se utiliza deste instrumento de capacitação docente também deveria dar maior atenção no sentido de realizar análises do valor final da qualificação, funcionando como espaço para a busca de métodos e pesquisas de aferição dos resultados. O propósito desse artigo, diante da escassez de trabalhos sobre o tema, é propriamente investigar de forma exploratória como se configura a influência da realização do estágio pós-doutoral sob a ótica da produção científica e bibliográfica, estando limitado à realidade institucional da pesquisa realizada na pós-graduação Stricto sensu da Universidade Federal Fluminense.

A proposição do pós-doutorado no cenário nacional é uma tentativa de incrementar de forma constante o desenvolvimento científico-tecnológico e da pesquisa, por meio da formação de recursos humanos com qualidade de alto nível, utilizando como instrumento os Pós-doc, como são nos nossos "corredores" da academia denominados os estágios de aperfeiçoamento em nível de pós-doutoramento.

Na Universidade Federal Fluminense - UFF, objeto desse estudo, o cenário geral não se distancia desse quadro atual; representando uma das instituições federais de ensino superior (UFRJ, UNIRIO, UFRRJ e UFF) que compõem o sistema estadual e que, com seus vários Campi, possui um expressivo peso sobre o sistema de pós-graduação do estado do Rio de Janeiro. O estudo aborda

1 Um pouco antes do fechamento deste artigo, surgiu um segundo trabalho analisando resultados do pós-doutorado. Trata-se de Castro e Porto (2010) recentemente publicado na Revista de Administração - RAUSP. Portanto, o artigo citado, não é propriamente o único, mas o primeiro desses mesmos autores. 
a configuração do "retorno" do estágio pós-doutoral, em termos da produção científica e tecnológica dos docentes atuantes na pós-graduação da UFF.

Mensurando as variações da produção em um panorama ex ante e ex-post, a pesquisa procura ampliar o escopo dos estudos desse campo de investigação para abranger também a realidade de uma universidade federal, que, por principio, pode possuir uma realidade bastante distinta em função de suas especificidades institucionais. Com objetivo de mapear a influência do estágio pós-doutoral sobre a produção dos docentes em programas de pós-graduação a pesquisa trabalhou, basicamente, utilizando como fonte de dados o Sistema Lattes, com a investigação objetiva sobre uma questão emblemática envolta no contexto da realização dos estágios pós-doutorais. O pós-doc contribui para aumentar a produção científica? Haveria diferenças significativas comparativamente à produção científica e bibliográfica antes e depois da realização do pós-doutorado?

\section{O ESTÁGIO PÓS-DOUTORAL E A ESFERA DA CAPACITAÇÃO PARA O CONHECIMENTO}

O pós-doutorado surge no cenário da pós-graduação como um item "extra" na carreira acadêmica que, considerando o atual escalonamento existente, tem seu ponto máximo de exigência o título de doutorado. A ideia inicial é potencializar o cenário da produção e disseminação da ciência e tecnologia, com vistas a ampliar a participação dos pesquisadores brasileiros no mainstream da ciência e facilitar a inserção do país na comunidade científica internacional.

O documento diretor CAPES/BEX (2008, p. 1) expõe que: "financia estágio pós-doutoral no exterior de professores e pesquisadores visando ao desenvolvimento de atividades de atualização, cooperação e abertura de novas linhas de pesquisa, sempre inseridas no contexto institucional de atuação do candidato".

Nesse sentido da cooperação entre professores e pesquisadores a tendência do pós-doutorado é atuar como uma oportunidade de complementação da formação por meio da inserção em um trabalho de pesquisa de ponta.

Quanto aos resultados empíricos, Castro e Porto (2008) consideram que um docente que tenha realizado tanto o doutorado pleno como também um estágio pós-doutoral no exterior, ou seja, que se capacite no exterior pela segunda vez, demonstra resultados compatíveis e em "pé de igualdade" com docentes que possuam a experiência pós-doutoral como o primeiro contato tácito com a realidade da pesquisa realizada no exterior. Segundo Pinho (2008, p. 
10), ao debruçar-se sobre o tema do retorno ao exterior para estágios pós-doutorais, "os dados surpreendem ao indicar que os índices ocupam praticamente os mesmos patamares, bem como constatam ser válida a volta ao exterior para contato com pesquisadores estrangeiros".

Castro e Porto (2010), em continuidade dos estudos, abordam notadamente que na realidade pós-doutoral, pelo menos nas hard sciences, não há heterogeneidade entre as áreas do conhecimento. Chegam a essa conclusão após não encontrar diferenças significativas na variação entre a produção antes e depois do pós-doutorado para as áreas de Biológicas, Engenharias, Exatas e da Terra e Saúde; todas as áreas possuem resultados bastante semelhantes. Apesar do aparente "contrassenso", esse resultado está confluente com os resultados de um amplo levantamento em base de dados do CNPq (Conselho Nacional de Desenvolvimento Científico e Tecnológico), apontados em Mocelin $(2009$, p. 56$)$ : "a comunidade científica se expande e produz mais em todas as áreas do conhecimento" e demonstra que no Brasil o crescimento do número de grupos de pesquisa e o crescimento da produção científica em periódicos e em eventos de qualidade é um fenômeno presente em todas as áreas do conhecimento.

Resta, no entanto, frisar que o trabalho de Mocelin (2009), não versa sobre a influência do estágio pós-doutoral; esse aumento de produtividade, segundo o autor, é resultante do próprio crescimento quantitativo do sistema que provoca a maior concorrência e também alianças entre pesquisadores. Apesar do estágio de pós-doutorado ser um dos possíveis instrumentos para se promover alianças entre pesquisadores, esse fenômeno não é objeto de análise ou discussão.

Além de pouco discutido, trata-se de um fenômeno recente, não havendo teoria específica que verse sobre o assunto. Os poucos trabalhos existentes como o de Castro e Porto (2008) e, bem recentemente, um segundo trabalho desses mesmos autores (CASTRO; PORTO, 2010) interpretam o pós-doutorado à luz da Gestão do Conhecimento. Para os autores, considerando que o pós-doutorado é um processo de interação entre universidades, em que pesquisadores são postos em contatos com instituições relacionadas com o estado da arte de uma determinada área, embute-se nesse processo a noção de que o pós-doutorado situa-se num espaço em que se mesclam ou se alternam condições de desenvolvimento e de aquisição de conhecimentos, via práticas de outros laboratórios de pesquisa e conectividade com outras práxis acadêmicas. Nesse processo de interação entre pesquisadores se estabelecem situações de aprendizagem, por meio de conhecimentos peculiarmente tácitos. 
Probst, Raub e Rombardt (2002) coloca que o conhecimento pode ser adquirido de especialistas externos, de outras organizações, de parceiros, de clientes, de vendedores ou de países "produtores" do conhecimento. Vale pontuar que embora a aquisição do conhecimento seja uma maneira rápida de inserir conhecimento, muitas vezes o conhecimento não está disponível para ser adquirido, o que dá força aos argumentos de criação de Nonaka e Takeuchi (1997) e coloca em pauta a difícil e árdua tarefa relacionada com a necessidade de desenvolver conhecimento nos contextos específicos.

Para Nonaka e Takeuchi (1997), a criação do conhecimento inicia-se no nível do indivíduo, estendendo-se para o grupo e posteriormente para a instituição, podendo atingir níveis interorganizacionais. Essa interação é refletida no Modelo de Conversão, composto por quatro modos: Socialização, Externalização, Combinação e Internalização (Figura 1).

O conhecimento para Nonaka e Takeuchi (1997) é subdividido em explícito e tácito. O conhecimento explícito (ou codificado) é capaz de ser transmitido por meio da linguagem formal e sistemática. Este conhecimento caracteriza-se pela capacidade de representado de forma compreensível para qualquer um que entenda a simbologia na qual ele é transmitido. O outro tipo relevante de conhecimento é o conhecimento tácito e que está associado à capacidade de agir das pessoas, às suas habilidades, expertises, experiências, competências, raciocínio, modelos mentais, gerações de ideias, opiniões, emoções, valores, intuição, concepção de mundo e crenças.

A socialização ou a disseminação do tácito ocorre com experiências compartilhadas. Não se trata de um aprendizado por meio da linguagem, mas pela observação via contato social, imitação e prática. Pela externalização, o conhecimento tácito é convertido em explícito, geralmente ocorre com a expressão do conhecimento por meio da linguagem, permitindo e provocando o diálogo e a reflexão coletiva. A combinação é a disseminação do explícito baseado na troca de codificáveis e a internalização, ou conversão do explícito em tácito. Este é incorporado às bases do indivíduo, sob a influência do seu modelo mental e transformado em comportamento. Da interação entre os quatro modos de conversão do conhecimento surge a espiral do conhecimento (Figura 1). A construção do conhecimento se inicia no nível do indivíduo e por meio da interação atinge gradativamente os grupos, equipes, setores, organizações, áreas e redes. 


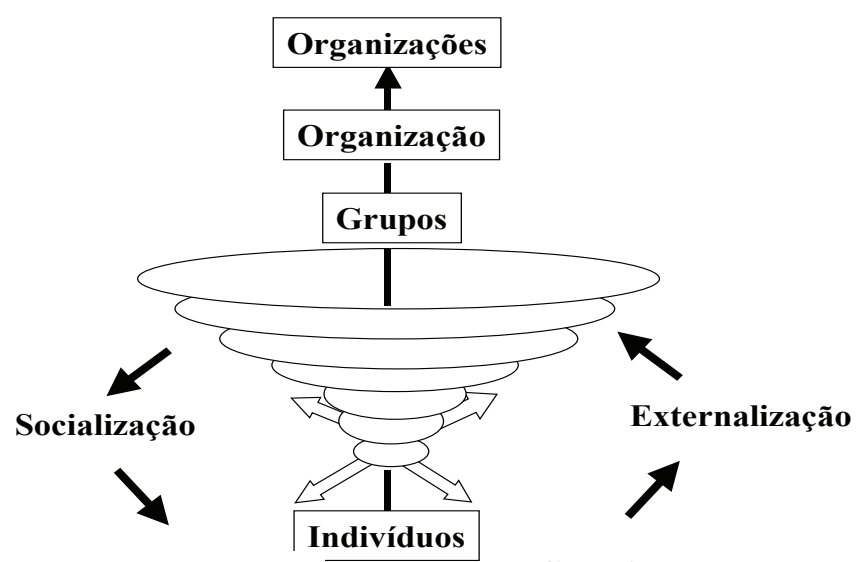

Internalização

Combinação

Figura 1 - Espiral do Conhecimento e a questão pós-doutoral.

Fonte: Elaboração própria - adaptado de Nonaka e Takeuchi (1997).

Vista como efeito do coletivo e influenciada pela disponibilidade de canais de comunicação, há uma gama de unidades de conhecimento inter-relacionadas que extrapolam a própria organização e são geradas por conectividade com outras instituições, universidades ou instituições de pesquisa (ANTONELLI, 1999). Dessa maneira as instituições beneficiam-se da proximidade para buscar crescimento por meio de um processo de co-evolução, ou seja, evoluir com a produção de conhecimentos inter-relacionados e complementares que extrapolam à própria organização, sendo geradas no caso do pósdoutorado por conectividade com outras universidades ou grupos de pesquisa (CASTRO; PORTO, 2008).

Tratando-se de conhecimento, compartilhar é um dos benefícios amplamente reconhecido pelas relações diretas em uma rede (POWELL, 1998; AJUHA, 2000; CALVOSA, 2010). Desse modo, quando as instituições colaboram para desenvolver uma pesquisa ou uma tecnologia/inovação, o conhecimento resultante estará disponível para todas as organizações parceiras. Então, cada parceiro recebe potencialmente uma quantidade maior de conhecimento, a partir de um projeto conjunto, em relação a um mesmo investimento de pesquisa de forma individual.

A complementaridade dos conhecimentos de uma organização, a partir do compartilhamento de informações com outras organizações é evidenciada por 
Angeloni (2005), e também, por Nonaka e Takeuchi (1997), ao apresentar a dimensão ontológica da criação do conhecimento. Diante dessa dimensão, o conhecimento nasce no nível individual, sendo expandido pela dinâmica da interação (socialização do conhecimento) e a dinâmica da espiral do conhecimento (Figura 1).

A "ampliação" de conhecimentos existentes ou a produção de novos conhecimentos surge quando a interação do conhecimento tácito e explícito eleva-se dinamicamente de um nível ontológico inferior até níveis mais altos. Nessa dimensão ontológica, observa-se que o conhecimento só é construído por indivíduos (NONAKA; TAKEUCHI, 1997). Uma rede inter-organizacional, como é o caso que se estabelece no pós-doutorado, não pode criar conhecimentos, pois o conhecimento só pode ser criado pelas pessoas que interagem na rede; mas as organizações participantes podem proporcionar um espaço de relações positivas e construtivas entre os atores e o ambiente. Assim, a partilha de informação, de opinião, de colaboração e de mobilização sobre um projeto confrontado às necessidades e ao desconhecido converge para a 'ampliação' do conhecimento das universidades participantes.

Pela externalização, o conhecimento tácito é convertido em explícito. Dessa forma, o estágio pós-doutoral de caráter eminentemente tácito deveria convergir para novas produções científicas e tecnológicas que possuem caráter explícito e podem ser compartilhados e disseminados pela comunidade acadêmica. Mas esse caminho não ocorre de forma tão direta e sem percalços.

Num artigo polêmico e com grande repercussão, Li e Gao (2003), procuraram demonstrar que o modelo tão discutido de criação de conhecimento proposto por Nonaka e Takeuchi (1997) é limitado se remetido ao conceito de conhecimento tácito de Michael Polanyi, que é o conceito originalmente proposto na década de 1950. Os autores da crítica remetem às origens o conceito 'tácito' e apontam que há generalismo no atual conceito de externalização, pois nem todos os conhecimentos tácitos podem vir a serem codificados por meio do simbolismo da linguagem, mas apenas em parte: os conhecimentos implícitos.

Polanyi (1966) diferencia implicitude de tacitude e a diferença básica entre ou dois conceitos é a capacidade ou potencialidade do conhecimento ser transferido e ensinado. O conhecimento tácito é aquele que não pode ser transferido; para Polanyi o tácito é propriedade de cada indivíduo e está arraigado nas práticas e formas particulares de agir e de conceber as coisas de cada pessoa enquanto ser. Nesse sentido, o tácito pode até vir a ser 'imitado', mas somente o conhecimento com implicitude potencial poderia ser trocado e compartilhado entre os indivíduos via externalização no futuro. 
O pós-doutorado pode ser visualizado como um local privilegiado para a complementaridade na formação de recursos humanos altamente especializados, com a geração de conhecimento vista como resultado de um empreendimento coletivo e fortemente influenciada pelos efetivos canais de comunicação entre os agentes aprendizes. Uma das características no processo de partilha de conhecimento entre os pesquisadores, pelo menos no que concerne ao estágio pós-doutoral, é a qualidade eminentemente tácita em que ocorre a interação.

O "tácito" ou o "implícito" transfere-se pela socialização, sendo que só é possível quando existe alguma proximidade que possibilite o contato, a socialização e a criação de uma base comum de conhecimento. A transferência de conhecimento depende da proximidade que pode fornecer acesso às redes relacionais locais. Nesse sentido, a lógica do pós-doutorado é incentivar essa "proximidade" visando o processo de desenvolvimento do conhecimento científico e tecnológico por meio da socialização entre pesquisadores em laboratório de primeira linha e relacionados com a produção de conhecimentos de fronteira. (CASTRO; PORTO, 2008)

O conhecimento científico explícito é definido como toda a forma de conhecimento codificado, facilmente estruturável e que tem possibilidade de ser comunicado por sistemas estruturados ou meios formais de comunicação. Compreende, então, todas as formas de literatura científica, avaliadas ou não. O conhecimento científico tácito, por sua vez, refere-se ao que pode ser entendido como o conhecimento ou habilidade que pode ser passada entre cientistas por contatos pessoais, mas não pode ser exposto ou passado em fórmulas, diagramas, descrições verbais ou instruções para ação. Para os autores Leite e Costa (2007, p. 94):

O conhecimento científico tácito é conhecimento baseado na informação científica, contudo está relacionado com a experiência e a competência do pesquisador, portanto de difícil sistematização e representação. Diz respeito àquele conhecimento que é mais bem transferido e assimilado informalmente.

Na procura de um modelo conceitual de gestão do conhecimento científico, Leite e Costa (2007) entendem que os sistemas de comunicação científica exercem importante papel para a criação, o compartilhamento e o uso do conhecimento científico. Para os autores, mesmo diante de meios mais formais de comunicação, como a exemplo das publicações, que são mais aptas a compartilhar conhecimento científico em sua vertente explícita, em contrapartida, 
o compartilhamento do conhecimento científico tácito requer necessariamente meios mais informais de comunicação.

A propriedade do conhecimento científico e da tecnologia deve ser vista com ressalva quando se considera a importância do conhecimento tácito para o processo de Ciência e Tecnologia. O conhecimento científico é codificado e formalizado, portanto pode ser transferido por outros meios que não a socialização. Neste sentido, ainda que a tecnologia esteja mais calcada no conhecimento científico, é importante esclarecer que o conhecimento tácito é relevante nos estágios iniciais do desenvolvimento, antes dos padrões terem sido estabelecidos e o design dominante ter sido fixado (DUNNING, 2000).

No campo da Gestão do Conhecimento, em que há predomínio de estudos qualitativos, Garvin (2001) realiza críticas e sugere o que denomina de a ideia de "Três Ms" como de utilidade para a gestão do conhecimento - Meaning, Management e Measurement. O autor defende claramente que devam existir também ferramentas de mensuração que possibilitem a avaliação da velocidade e dos níveis de aprendizado da organização, uma vez que é impossível gerenciar o que não se pode mensurar.

Esforços vêm sendo empreendidos na tentativa de elaborar métodos de gestão desse ativo intangível - o conhecimento. Krogh, Ichijo e Nonaka (2001) questionam o emprego do termo gestão, que traz em si a ideia de controle ou de administração racional, e argumentam que, não podendo ser controlado, o conhecimento não poderia ser "gerido". Os autores, focando as pessoas, frisam a necessidade de desenvolver "ativistas" do conhecimento e, argumentando pelo não uso do termo gestão de conhecimento, optam pela utilização da expressão capacitação para o conhecimento. Vale frisar: tratase de (re)posicionamento, do próprio Nonaka, um dos nomes expressivos na área de gestão do conhecimento.

$\mathrm{Na}$ esfera da capacitação para o conhecimento, a questão envolta no pósdoutorado é, então, fomentar o contato de doutores brasileiros com os melhores programas no país ou fora do país, tendo em vista que, a formação de recursos humanos de primeira linha requer a aquisição de conhecimentos de fronteira e a socialização em ambientes nos quais ele é gerado, com a expectativa de que com o estágio pós-doutoral, haja benefícios no trabalho e produção docente, bem como, benefícios ou impacto positivo para o programa de pós-graduação de origem (CASTRO; PORTO, 2010).

O pós-doutorado com propósitos eminentemente de transferência de conhecimentos científicos e tecnológicos de fronteira por meio da Socialização - nos moldes de Nonaka e Takeuchi (1997), também não pode ou não 
deveria ficar restrito ao contexto da socialização, mas sim, ao sair do período de "incubação", não ficar em situações de isolamento. Deveria se ampliar por meio de interação e compartilhamento para processos de Externalização do conhecimento, para que possa ser conhecido pelos demais membros da comunidade científica. Trilhando-se esse caminho, o conhecimento explícito é formal e sistematizado, portanto, passível de ser comunicado e compartilhado, e no caso específico desse estudo, também passível de ser observável e mensurável.

O conhecimento científico é o conhecimento racional e sistemático, desse modo, tendo-se em perspectiva o pós-doutorado como um processo que visa incremento do conhecimento - nesse caso em especial do conhecimento científico. A presente pesquisa buscou então concentrar os esforços de mensuração em torno do conhecimento externalizado, que se traduz no conhecimento cristalizado sob a forma de publicações científicas e bibliográficas que são compartilhadas pela comunidade acadêmica.

\section{MÉTODO}

A captação de dados relativos à produção acadêmica/docente num panorama ex-ante e ex-post teve como fonte principal a busca em dados secundários, especialmente, tendo por base o sistema Lattes. A população da pesquisa foi constituída pelos docentes das áreas dispostas na Tabela 1, atuantes na pósgraduação da Universidade Federal Fluminense que realizaram/concluíram o pós-doutorado (e/ou que atualizaram essa informação no sistema Lattes) até junho de 2008. O levantamento de dados foi realizado de forma censitária, abarcando, sem exceções, todos os docentes que satisfizeram a esse quesito.

Seguindo padrões nacionais, adota-se aqui o critério Qualis ${ }^{(2)}$; utilizado por diversas áreas, que leva em consideração tanto a quantidade (número de publicações) como a qualidade, que expressa pela base de avaliação CAPES, em princípio, refletiria a qualidade dos veículos ou meios de divulgação científica. No que se refere à indexação, Souza e Paula (2002), aborda que um periódico indexado passa a compor uma base sobre o qual se fundamentarão indicadores bibliométricos, entre eles, o número de citações. Nesse sentido, base e indicadores desenvolvidos pelo Institute for Scientific Information (ISI) e publicados no Science Citation Index (SCI) têm grande aceitação na comunidade científica.

O fator de impacto do Journal of Citation Report (JCR) também tem boa aceitação nestas quatro áreas investigadas, que o levam em consideração 
no momento de classificação dos periódicos utilizados para divulgação das pesquisas e trabalhos científicos. Mas, o que se compreende por qualidade é bastante subjetivo, sendo que parte dessa avaliação advém da opinião dos "pares" e do conhecimento que componentes das comissões de área/ avaliação têm dos veículos utilizados pelos programas de pós-graduação (SOUZA; PAULA, 2002).

Em sintonia com os argumentos de Castro e Porto (2008), o presente estudo também considera o pós-doutorado como uma comunidade de prática, com ampliação de conhecimentos via socialização; o pós-doc, posteriormente, transporia a essa situação de socialização (conhecimento tácito) e auxiliaria em incrementos de publicações científicas (conhecimento explícito). Com esse pressuposto, estruturou-se pesquisa exaustiva e objetiva do que os docentes produziam e realizavam em pesquisa antes do pós-doutorado e o que efetivamente produziram na pós-graduação da Universidade Federal Fluminense, após a realização do estágio em nível do pós-doutorado.

Com a perspectiva do Qualis, o presente estudo trabalhou basicamente utilizando como fonte de dados o Sistema Lattes, com uma pesquisa exaustiva e objetiva do que os docentes produziam em pesquisa antes do pósdoutorado e o que efetivamente produziram após sua realização. O efeito investigado foi baseado na análise da variação da produção científica e bibliográfica; portanto, vale frisar, que a dimensão do efeito investigado nesse patamar não cobre efeitos em amplitude sobre o trabalho docente, pois não foram analisados efeitos no ensino e/ou na extensão universitária. A dimensão do efeito, neste âmbito, cobre basicamente a produção nas atividades de pesquisa da pós-graduação e produtividade em C\&T.

Com essa perspectiva, a forma de ponderação da produção acadêmica descrita nos trabalhos de Castro e Porto $(2008,2010)$ para a investigação da produção científica e bibliográfica no contexto da realização dos pós-doutorados foi, aqui, também utilizada. A ponderação proposta tem por base o estabelecimento de uma pontuação para cada tipo de produção bibliográfica e são indicadores construídos e influenciados a partir das relações e das ponderações aplicadas por diversas comissões/comitês de área da CAPES. Essas ponderações ou "pesos" dados a cada tipo de produção científica e bibliográfica são diversas, o cômputo geral utilizado (Tabela 2) com a série de pontuações tenta refletir uma tendência que, de certo modo, torna possível um cotejamento amplo como o que se propõe o presente estudo. 
Tabela 1 - Detalhamento da composição das grandes áreas

\begin{tabular}{lll}
\hline Biológicas & Sociais Aplicadas & Engenharias \\
\hline Biologia Geral & Administração & Eng. Aeroespacial \\
Biofísica & Arquitetura e Urbanismo & Eng. Biomédica \\
Bioquímica & Ciência da Informação & Eng. Civil \\
Botânica & Comunicação & Eng. de Materiais \\
Ecologia & Contábeis & Eng. de Minas \\
Farmacologia & Demografia & Eng. de Produção \\
Fisiologia & Desenho Industrial & Eng. de Transportes \\
Genética e Melhoramento & Direito & Eng. Elétrica \\
Imunologia & Economia & Eng. Mecânica \\
Microbiologia & Museologia & Eng. Oceânica \\
Morfologia & Planejamento Urb.e Regional & Eng. Nuclear \\
Parasitologia & Serviço Social & Eng. Química \\
Zoologia & Turismo & Eng. Sanitária \\
\hline Saúde & Humanas & Exatas e da Terra \\
\hline Educação Física & Antropologia & Astronomia \\
Enfermagem & Arqueologia & Computação \\
Farmácia & Ciência Política & Física \\
Fisioterapia & Educação & Química \\
Terapia Ocupacional & Filosofia & Geociências \\
Fonoaudiologia & Geografia & Matemática \\
Medicina & História & Oceanografia \\
Nutrição & Psicologia & Estatística \\
Odontologia & Sociologia & \\
Saúde Coletiva & Teologia & Multidisciplinar \\
\hline Agrárias & Letras, Lingüística e Artes & Multidisciplinares, conforme \\
\hline Agronomia & Artes & classificados pelos comitês \\
Engenharia Agrícola & Letras & \\
Engenharia Florestal & Lingüística & \\
Engenharia de Pesca & & \\
Medicina Veterinária & & \\
Tecnologia de Alimentos & & \\
Zootecnia & & \\
\hline & & \\
\hline & & \\
\hline
\end{tabular}

Fonte: Informações constantes em www.capes.gov.br, home-page da CAPES. (maio, 2007)

(1) Cabe registrar que a coleta de dados da pesquisa ocorreu anteriormente à (re)estruturação da base Qualis que ocorreu em meados do ano de 2009.

Com o critério de atribuição de pontos para cada uma das atividades, o componente publicações é composto por todas essas dimensões descritas na tabela 2 e sua mensuração ocorre pela simples soma dos pontos correspondentes a cada uma das atividades inerentes ao componente de produção científica e bibliográfica que compõe o índice. 
Tabela 2 - Ponderação utilizada para mensuração de produção acadêmica em pesquisa

\begin{tabular}{lclclc}
\hline Periódicos & Pontuação Livros & Pontuação & $\begin{array}{l}\text { Demais tipos de } \\
\text { produção }\end{array}$ & Pontuação \\
\hline Internacional A & 18 & Livros publicados & 10 & Prefácio, posfácio & 3 \\
\hline Internacional B & 12 & Livros organizados & 7 & Tradução de livro & 7 \\
\hline Internacional C & 6 & Capítulos de livro & 5 & Partitura & 3 \\
\hline Nacional A & 10 & Anais & & $\begin{array}{l}\text { Textos em Jornais/ } \\
\text { revistas }\end{array}$ & 1 \\
\hline Nacional B & 7 & Eventos A & 7 & Outras traduções & 3 \\
\hline Nacional C & 4 & Eventos B & 3 & $\begin{array}{l}\text { Periódico não } \\
\text { constante do } \\
\text { Lualis }\end{array}$ & 2 \\
\hline Local A & 5 & Eventos C & 1 & $\begin{array}{l}\text { Demais produções } \\
\text { relevantes listadas } \\
\text { pelo pesquisador }\end{array}$ & 2 \\
\hline Local C & 3 & Não Classificados & 1 & 1 & \\
\hline
\end{tabular}

A sistemática do Qualis baseia-se na indexação das revistas científicas e na participação qualitativa da comunidade científica, por meio das Comissões de Área da CAPES. O maior peso ou importância atribuída a periódicos, mesmo que controverso, justifica-se pela própria natureza e identidade da pósgraduação Stricto sensu. No que tange ao balizamento utilizado, sobre a base Qualis utilizada no estudo, no que se refere à classificação, especialmente das revistas científicas, adotava dois critérios básicos: a abrangência da circulação (Internacional, Nacional e Local) e níveis de qualidade (A, B, C).

Segundo Souza e Paula (2002), as áreas do conhecimento que compõem a Tabela 1 fazem uso do Qualis e contemplam critérios editoriais; adotando-se os serviços do ISI ou do JCR e às vezes aplicando-se outros critérios objetivos tais como: tiragem, periodicidade, divulgação, padronização, normalização, etc.; sobre o que se compreende por qualidade no interior de cada área, observa-se que a classificação de um periódico como "A", "B" ou " $C$ " ainda envolve componente subjetivo, com a representação dos "pares" e das comissões de área. Cabe o registro que essa sistemática de classificação sofreu alterações, por meio de um recente documento de caráter normativo CAPES/CTC (2009), os veículos periódicos de divulgação científica passaram a ser enquadrados em estratos indicativos da qualidade - desde o A1, o mais elevado, que soma 100 pontos, passando pelos seguintes: A2; B1; B2; B3; B4; B5 e C, o último nível, com peso zero.

A utilização da base Qualis, por envolver a questão qualidade, é essencialmente polêmica, mas o propósito aqui não é a avaliação de cursos. Assim, vale apontar que a forma como a tabela de pontos está estruturada não bene- 
ficia nem prejudica a nenhuma das áreas do conhecimento. Isso porque, em nenhum momento, serão atribuídos conceitos como "Bom", "Muito bom", "Ruim" ou "Deficiente" para a pontuação obtida.

As colocações aqui serão, por exemplo, do tipo: em Biológicas existia uma média de $\mathrm{X}$ pontos/ano no quesito publicações, e após a realização do pós-doutorado por seus docentes essa média passou a ser Y pontos/ano. Ao referenciar-se a base Qualis, o trabalho a utiliza como uma referência e como um instrumental para buscar equacionar melhor as publicações científicas e as bibliográficas, adotando-se como procedimento metodológico aplicar a classificação com base nos critérios estabelecidos e adotados à época por cada área, não cabendo na pesquisa aqui refutá-los.

\section{RESULTADOS E DISCUSSÃO}

A meta do presente trabalho foi realizar uma avaliação de influência de forma censitária, abarcando todos os docentes pesquisadores do quadro da UFF. No entanto, a primeira ressalva nesse quesito é que, apesar de meta censitária, é plausível que alguns docentes não componham a presente população por motivos adversos como a realização do pós-doc. com um término após dezembro/2008, bem como, a possibilidade iminente de defasagem das informações contidas no sistema Lattes, a exemplo do docente ter atualizado o currículo Lattes após a coleta de dados e, assim, com o gap temporal haver alguma dissonância entre o informado/alimentado pelo docente e o efetivamente realizado em termos das produções científicas e bibliográficas.

Mesmo pressupondo-se a priori que o índice de participação de $100 \%$ não tenha sido efetivamente concretizado, índices bem próximos a esse patamar devem ter sido alcançados na instituição investigada. A população inicial contou com 283 docentes, no entanto em função de inconsistências encontradas nas informações contidas no currículo Lattes, cinco docentes não foram considerados para análise ${ }^{(3)}$. Dessa forma, a população de docentes da universidade que realizaram estágios pós-doutorais totalizou 278 docentes pesquisadores, sendo 106 docentes $(38,1 \%)$ do sexo feminino e 172 docentes $(61,9 \%)$ do sexo masculino.

(2) Como exemplo de inconsistências encontradas, havia currículos que informavam realização e término do pós-doutorado antes da conclusão efetiva do doutorado.

A distribuição dos docentes que realizam pós-doutorado e suas respectivas áreas (Tabela 3 ) demonstrou que mais de $1 / 3$ dos pós-docs. realizados 
na UFF $(34,2 \%)$ são de docentes da área de Exatas, sendo que encontram-se especialmente concentrados nas áreas de Física $(11,9 \%)$ e de Química $(8,3 \%)$, claramente indicando que há uma maior procura dos docentes dessas áreas acadêmicas da UFF para o complemento de estudos por meio do estágio de pós-doutorado.

Ao considerar-se de forma isolada a área em si, independentemente da grande área do conhecimento, nota-se que além das áreas de Química e Física, há uma grande procura em algumas das outras áreas do conhecimento, tanto pertencente à grande área de exatas (Matemática - 6,5\%), quanto fora desta, como: História (9\%), Letras (8,6\%), Medicina (5,8\%) e Antropologia (4\%). Chama a atenção, para efeitos de um cotejamento, a perspectiva de que a área de História possui na instituição um número de doutores que realizaram pósdoutorado que é equivalente a toda a grande área de saúde.

A distribuição dos docentes na Universidade Federal Fluminense de acordo com o ano da realização do estágio pós-doutoral (Figura 2) possui como média o ano de 2000, com desvio padrão de 6,5 anos; tendo o mínimo de 1980, o máximo de 2008 e uma mediana de 2002; indicando que a procura ou demanda pela realização do "Estágio Pós-Doutoral" é um fenômeno essencialmente recente. Nota-se que em toda a década de 1980 e nos cinco primeiros anos da década de 1990 registra-se um cenário bastante diferenciado em relação ao que acontece nos anos finais da década de noventa e especialmente a partir de 2001, em que ocorreu de forma sistemática o registro de aumentos expressivos da realização dos estágios e com uma tendência que se manteve praticamente constante.

A aparente queda em 2008 pode ser atribuída por inferência mais ao corte da pesquisa, que, como dito anteriormente foi junho/2008, do que propriamente a uma reversão do comportamento dos dados empíricos (Figura2). Em relação ao perfil dos doutores que realizaram estágios pós-doutorais (Figura 3), observa-se que há uma predominância dos recém-doutores e há um menor interesse pelos docentes que estão em uma fase aqui denominada de intermediária (entre cinco e oito anos, após a conclusão do doutorado), mas apesar da polaridade entre as categorias Sênior e Recémdoutor, há uma distribuição relativamente equilibrada entre os diversos estágios da carreira. 
Tabela 3 - Distribuição dos docentes com pós-doutorado na UFF e suas respectivas áreas.

\begin{tabular}{|c|c|c|c|c|c|}
\hline Área & Número & Percentual & Área & Número & Percentual \\
\hline Biofísica & 3 & $1,1 \%$ & & & \\
\hline Bioquímica & 2 & $0,7 \%$ & Administração & 1 & $0,4 \%$ \\
\hline Ecologia & 4 & $1,5 \%$ & Arquitetura e Urbanismo & 2 & $0,7 \%$ \\
\hline Farmacologia & 6 & $2,2 \%$ & Ciência da Informação & 2 & $0,7 \%$ \\
\hline Fisiologia & 3 & $1,1 \%$ & Comunicação & 2 & $0,7 \%$ \\
\hline Imunologia & 2 & $0,7 \%$ & Direito & 1 & $0,4 \%$ \\
\hline Microbiologia & 4 & $1,4 \%$ & Economia & 5 & $1,8 \%$ \\
\hline Morfologia & 1 & $0,4 \%$ & Serviço Social & 1 & $0,4 \%$ \\
\hline Parasitologia & 2 & $0,7 \%$ & \multirow{2}{*}{$\begin{array}{l}\text { Planejamento Urbano e } \\
\text { Regional }\end{array}$} & \multirow{2}{*}{1} & \multirow{2}{*}{$0,4 \%$} \\
\hline Zoologia & 2 & $0,7 \%$ & & & \\
\hline Biológicas & 29 & $10,4 \%$ & Sociais Aplicadas & 15 & $5,4 \%$ \\
\hline Engenharia Civil & 4 & $1,4 \%$ & Enfermagem & 1 & $0,4 \%$ \\
\hline $\begin{array}{l}\text { Engenharia de } \\
\text { Materiais }\end{array}$ & 2 & $0,7 \%$ & Engenharia Biomédica* & 1 & $0,4 \%$ \\
\hline $\begin{array}{l}\text { Engenharia de } \\
\text { Produção }\end{array}$ & 2 & $0,7 \%$ & Farmácia & 1 & $0,4 \%$ \\
\hline $\begin{array}{l}\text { Engenharia de } \\
\text { Transportes }\end{array}$ & 1 & $0,4 \%$ & Medicina & 16 & $5,8 \%$ \\
\hline Engenharia Elétrica & 3 & $1,1 \%$ & Nutrição & 1 & $0,4 \%$ \\
\hline Engenharia Mecânica & 3 & $1,1 \%$ & Odontologia & 2 & $0,7 \%$ \\
\hline Engenharia Oceânica & 2 & $0,7 \%$ & Saúde Coletiva & 3 & $1,1 \%$ \\
\hline Engenharias & 17 & $6,1 \%$ & Saúde & 25 & $9 \%$ \\
\hline Antropologia & 11 & $4 \%$ & & & \\
\hline Ciência Política & 6 & $2,2 \%$ & Computação & 6 & $2,2 \%$ \\
\hline Educação & 6 & $2,2 \%$ & Física & 33 & $11,9 \%$ \\
\hline Filosofia & 4 & $1,4 \%$ & Química & 23 & $8,3 \%$ \\
\hline Geografia & 2 & $0,7 \%$ & Geociências & 6 & $2,2 \%$ \\
\hline História & 25 & $9 \%$ & Matemática & 18 & $6,5 \%$ \\
\hline Psicologia & 4 & $1,4 \%$ & Oceanografia & 7 & $2,5 \%$ \\
\hline Sociologia & 2 & $0,7 \%$ & Estatística & 2 & $0,7 \%$ \\
\hline Humanas & 60 & $21,6 \%$ & Exatas e da Terra & 95 & $34,2 \%$ \\
\hline Agronomia & 1 & $0,4 \%$ & & & \\
\hline Medicina Veterinária & 3 & $1,1 \%$ & Artes & 2 & $0,7 \%$ \\
\hline $\begin{array}{l}\text { Tecnologia de } \\
\text { Alimentos }\end{array}$ & 3 & $1,1 \%$ & Letras & 24 & $8,6 \%$ \\
\hline Zootecnia & 1 & $0,4 \%$ & Linguística & 3 & $1,1 \%$ \\
\hline Agrárias & 8 & $2,9 \%$ & $\begin{array}{l}\text { Letras, } \\
\text { Lingüística e Artes }\end{array}$ & 29 & $10,4 \%$ \\
\hline Total & 278 & $100,0 \%$ & & & \\
\hline
\end{tabular}

*Apesar da CAPES, classificar como engenharias, o docente se identifica como sendo da área de saúde 


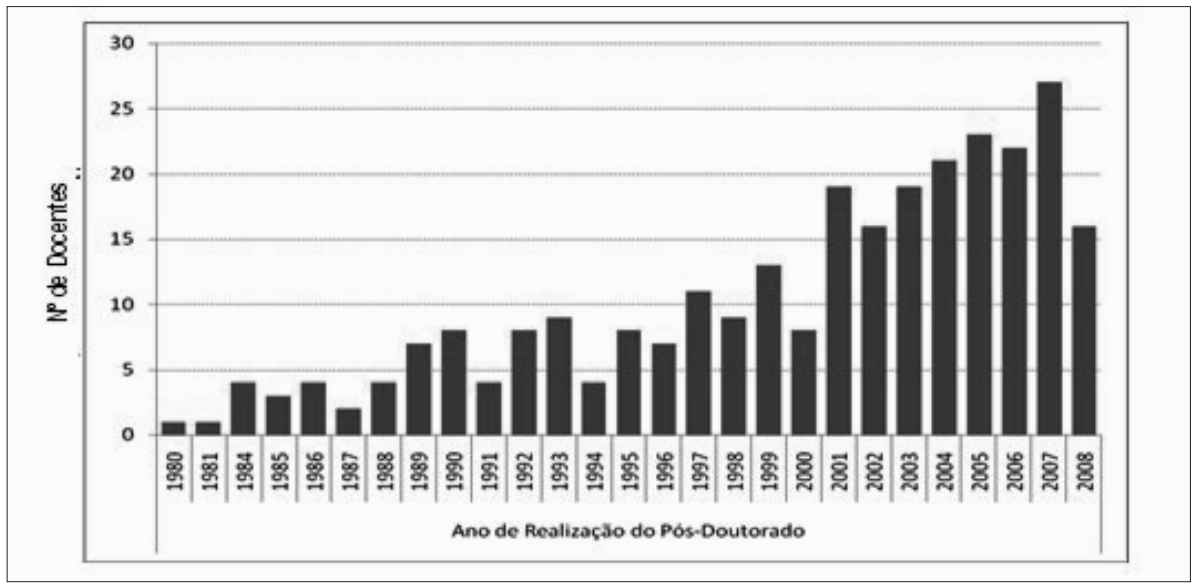

Figura 2 - Distribuição do Ano do Pós-doutorado Realizado pelos Docentes da UFF.

Fonte: Dados da pesquisa.

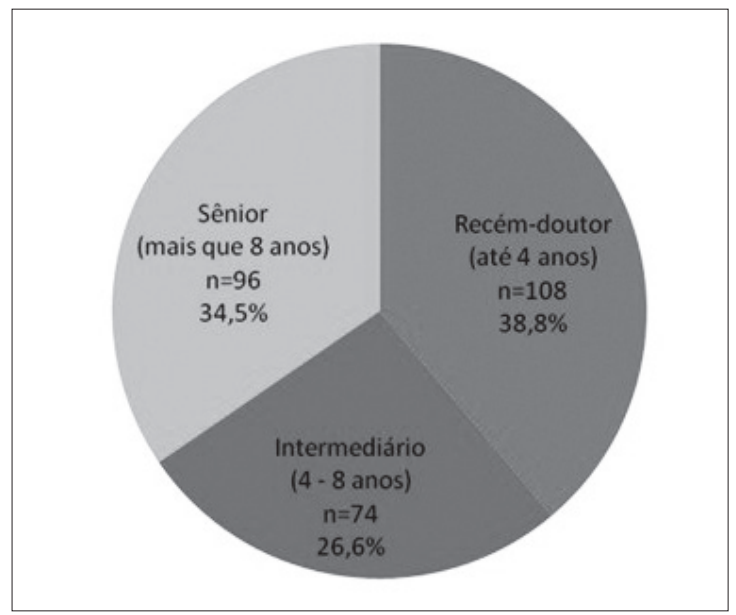

Figura 3 - Perfil da categoria docente à época da realização do pós-doutorado

Fonte: Dados da pesquisa

Em relação ao país de realização do pós-doutorado (Figura 4) tem-se a predominância da realização do pós-doutorado no próprio país - 34\% dos casos, seguido pelos Estados Unidos com 26 \% e pela França com 19,1\%. No que tange especificamente aos pós-doutorados realizados no exterior, os Estados Unidos são o país predominante e representam, sozinho, $40 \%$ dos estágios realizados fora do país, mas há um destaque também para países da Europa 
- Alemanha, França, Inglaterra e, em menor grau, Espanha, Itália, Portugal e demais países. A participação da América Latina, como um todo, é pequena e representa pouco mais de $1 \%$ dos casos.

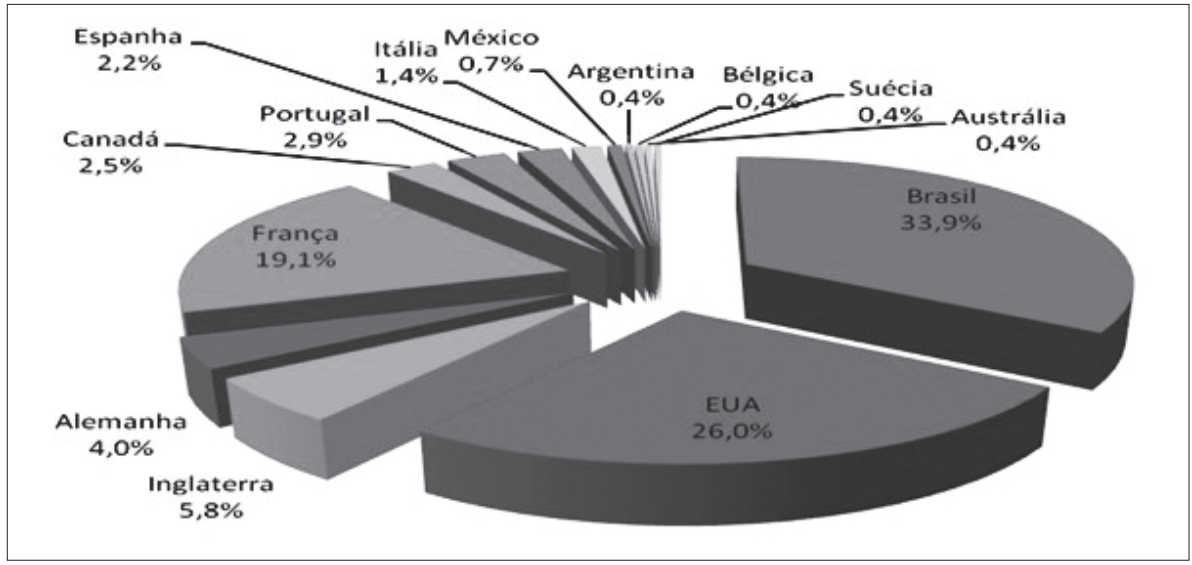

Figura 4 - Distribuição da escolha dos docentes em relação ao país de realização do pós-doutorado.

Fonte: Dados da pesquisa.

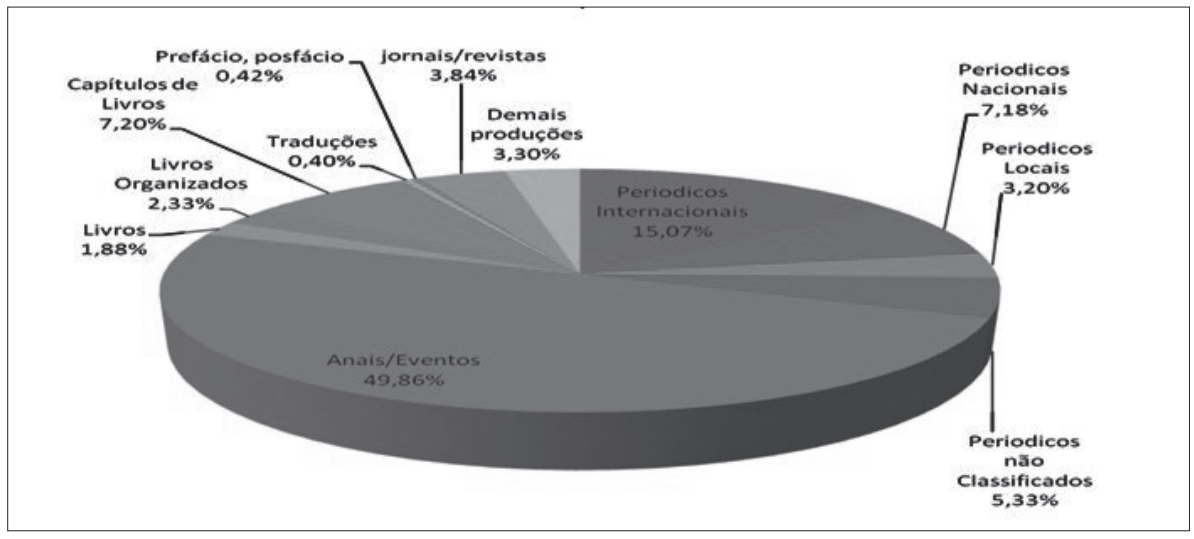

Figura 5 - Distribuição geral da produção com a escolha dos docentes em relação ao veículo de divulgação dos trabalhos.

Fonte: Dados da pesquisa. 
No que diz respeito à escolha dos veículos e forma de divulgação dos trabalhos acadêmicos, a Figura 5 ilustra a distribuição geral das produções científicas e bibliográficas realizadas pelos docentes da UFF. Há o predomínio claro de que se privilegia a publicação em anais de eventos, que representa em termos absolutos $50 \%$ das produções realizadas pelos docentes. Do lado oposto tem-se a baixa realização de traduções de livros e outras traduções, bem como de convites para concretizar publicações de prefácios e/ou de posfácios. Quadro esse desenhado em termos absolutos da produção, mas como se estabelece a produção em termos relativos? Pois, apesar de tão diversos, os vários meios escolhidos, possuem amplitude e relevância para a pesquisa também bastante diversas e diferenciadas.

Em relação aos indicadores bibliométricos aqui utilizados para identificar a influência dos estágios pós-doutorais realizados por docentes da Universidade Federal Fluminense, levou-se em consideração a produção dos docentes ao longo da carreira ponderada pelos valores dispostos da Tabela 2, obtendo-se um score de produção em termos de 'pontos/ano' para cada um dos docentes pesquisados para o período anterior ao pós-doutorado e, seguindo-se a mesma ponderação, obteve-se um score para o período subsequente ao pós-doutorado.

A variação da produção considera e registra a diferença de pontos/ano do docente nesses dois momentos. Assim, uma variação geral da produção da ordem de 0,5 representa um acréscimo de $50 \%$ em relação à pontuação anual que o docente apresentava antes da realização do pós-doutorado. Uma variação de zero significa uma produção estável. Uma variação de -0,1 representa uma queda de $10 \%$, e assim por diante.

Tabela 4 - Relação entre o perfil docente e a variação média da produção antes e depois do pós-doutorado

\begin{tabular}{lccc}
\hline \multicolumn{1}{c}{ Perfil docente } & Variação média & Desvio padrão & $\mathbf{n}$ \\
\hline Sênior & 1,4202 & 9,8936 & 96 \\
Intermediário & 0,1659 & 1,4609 & 74 \\
Recém-doutor & $-0,2256$ & 0,9094 & 108 \\
\hline Geral UFF & 0,4469 & 5,914 & 278 \\
\hline
\end{tabular}

A Tabela 4 traz os dados relativos à variação da produção e os respectivos perfis docentes em relação ao tempo de carreira. Observa-se que para os re- 
cém-doutores que optaram por realizar o pós-doutorado a produção científica e bibliográfica apresentada segue com um padrão médio de queda em relação ao ritmo de produção que era verificado antes da realização do estágio pósdoutoral - em média $22 \%$ menor. Os docentes que realizaram o pós-doutorado entre cinco e oito anos após a conclusão do doutorado, apresentaram melhoras no desempenho, obtendo um ganho em média, $16 \%$ superior. O resultado mais expressivo, no entanto, é que há um salto da produção, na verdade um grande salto da produção para os doutores seniores, que em média mais do que dobram a pontuação após o término do estágio. Mas antes que se comemore esse resultado, é bom o aviso que "nem tudo são flores".

O grande salto da produção ponderada, verificado para os doutores seniores, encontra-se associado também a um elevado desvio-padrão, o que significa que há uma grande dispersão em torno da média apresentada. Em outras palavras, há o registro de uma tendência de aumento - na verdade de um considerável aumento -, mas não representaria uma regra geral para os doutores seniores, o alto desvio-padrão denuncia que o registro de incremento da produção é válido para alguns, não é válido para outros. A média apresentada não reflete uma tendência do grupo como um todo.

Claro que se tem que ponderar que, de qualquer forma, mesmo que não tão categórico do ponto de vista estatístico, esse resultado é ainda bastante expressivo, afinal cria um cenário ou expectativa diferenciada principalmente em relação ao resultado apresentado pelos recém-doutores, onde a tendência foi o de não haver diferenças entre o antes e o depois, com o registro inclusive de queda da produção com uma tendência apontada pela média.

\section{CONSIDERAÇÕES FINAIS}

A variação relativa e ponderada da produção para efeitos da Tabela 4 considera e registra a diferença de publicações/ano do docente nos dois momentos (antes e depois). Sendo que uma variação média da produção de ordem positiva representa acréscimo em relação ao número de publicações anual que o docente apresentava antes da realização do pós-doutorado. Uma variação de zero, significa uma produção estável. Uma variação negativa representa uma queda quantitativa e assim por diante.

No cenário exposto, a presente pesquisa, ao se inserir na proposição da qualificação docente, apesar de utilizar população diferente e método diferente, retrata a ideia de que os dados reforçam o caráter opcional do pós-doutorado, enquanto um instrumento que venha agregar valor na carreira docente, 
retratado em Castro, Porto e Kannebley Jr. (2009). Com referência aos doutores seniores da UFF, há a tendência clara de aumento da produção, mas esse aumento é disperso e não válido para qualquer docente da categoria "sênior". Isso implica em considerar que o pós-doutorado não é item primordial para diferenciar a produção ou alavancar a carreira, mas sim opcional, tendo em vista que se não para todos, torna-se bastante útil para a realidade de alguns docentes.

O grande salto da produção ponderada de alguns doutores seniores pode ser explicado, entre outras coisas, por uma migração das publicações para revistas internacionais que possuem peso maior na forma do cálculo estruturado. Pode ser explicado também pelo próprio amadurecimento da carreira que, aliado a um pós-doutorado, favorece a ampliação da rede de relacionamentos, e que segundo a literatura da capacitação ou gestão do conhecimento seria elementos que aliados podem fornecer resultados positivos. Podem ser explicados também pelo fato, de que se o pesquisador sênior vinha desenvolvendo pesquisa de forma individualizada ao longo do tempo, o pós-doc nesse momento se revestiu como uma boa oportunidade para se rever conceitos, conhecer e interagir com diferentes ambientes acadêmicos, quebrando-se endogenia da pesquisa e promovendo a atualização e a reciclagem.

Nesse mesmo sentido, pode se concretizar o fato que um recém-doutor não demonstre resultados tão favoráveis; afinal, por princípio e conceito, se o pós-doutorado visa a uma oportunidade de atualização, é plausível que após a conclusão do doutorado, o pesquisador esteja atualizado e por isso em consonância com o estado da arte e talvez não necessitando de um pós-doc de uma forma tão imediata. Decisão que obviamente é de caráter individual, mas se o objetivo do pós-doutorado visa a um start pelo processo de socialização para posterior incremento na produção, os pós-doutorados realizados na UFF - pelos recém-doutores - não estão atendendo a essa expectativa.

Por fim, como importante ressalva tem-se o fato de que as atividades da pós-graduação não se restringem às atividades de pesquisa. A produtividade aqui mensurada ficou circunscrita a questões vinculadas às atividades de Pesquisa, mas dimensões de Ensino e, também, de Extensão, presentes na pósgraduação poderiam ser merecedores de uma atenção especial, sendo este um aspecto de limitação de escopo do trabalho. Mas que pode (e deve) merecer destaque especial em pesquisas, principalmente em um assunto de caráter ainda predominantemente exploratório, para que assim também se trilhe caminho em outras vertentes e que poderiam ser ampliadas. 


\section{REFERÊNCIAS}

AJUHA, G. Collaboration networks, structural holes, and innovation: a longitudinal study. Administrative Science Quarterly, New York, v. 45, n. 3, p. 425-455, Sep. 2000.

ANGELONI, M. T. (Coord.). Organizações do conhecimento. São Paulo: Saraiva, 2005.

ANTONELLI, C. The evolution of the industrial organization of the production of knowledge Cambridge Journal of Economics, Oxford. v. 23, p. 243-260, 1999.

\section{CAPES/BEX. Orientações para candidatos a Estágio Pós-Doutoral no} exterior. Documento. Brasília, 2008. Disponível em: <http://www.CAPES. gov.br/>. Acesso em: mar. 2008.

CAPES/CTC. Reestruturação do Qualis. Documento do Conselho Técnico Científico. Brasília, 2009. Disponível em: <http://www.CAPES.gov.br/>. Acesso em: maio 2009.

CASTRO, P. M. R.; PORTO, G. S. Retorno ao exterior vale a pena? A questão dos estágios pós-doutorais sob a perspectiva da produção em C\&T. Organizações \& Sociedade, Salvador, v. 15, n. 47, p. 155-173, 2008.

CASTRO, P. M. R.; PORTO, G. S. Análise exploratória sobre avaliação e mensuração de resultados da capacitação via estágios pós-doutorais: heterogeneidade entre grandes áreas do conhecimento? Revista de Administração - RAUSP, São Paulo. v. 45, n. 1, p. 43-56, 2010.

CASTRO, P. M. R.; PORTO, G. S.; KANNEBLEY JÚNIOR, S. Pós-doutorado, Essencial ou Opcional? Uma radiografia crítica no que diz respeito às contribuições para a produção científica. In: ENCONTRO DA ASSOCIAÇÃO NACIONAL DE PÓS-GRADUAÇÃO E PESQUISA EM ADMINISTRAÇÃO, 33., 2009, São Paulo. Anais... São Paulo: ANPAD, 2009.

CALVOSA, Marcello. Tecnologia e organização do trabalho. Rio de Janeiro: CECIERJ, 2010.

DUNNING, J. (Ed.) Regions, globalization and the knowledge economy: the issues stated in regions, globalization and the knowledge-based economy. Oxford: University Press, 2000. 
GARVIN, D. Gestão do conhecimento: construção da organização que aprende. In: HARVARD BUSINESS REVIEW BOOK. Rio de Janeiro: Campus, 2001. p. 50-81.

GOERGEN, P. Ciência, sociedade e universidade. Educação \& Sociedade, Campinas, v. 19, n. 63, p. 53-79, 1998.

KROGH, G.; ICHIJO, K.; NONAKA, I. Facilitando a criação do conhecimento: reinventando a organização com poder de inovação contínua. São Paulo: Campus, 2001.

LEITE, F. C. L.; COSTA, S.M.S. Gestão do conhecimento científico. Ciência da Informação, Brasília, v. 36, n. 1, p. 92-107, 2007.

LI, M.; GAO, F. Why Nonaka highlights tacit knowledge: a critical review. Journal of Knowledge Management. Bradford, UK, v. 7, n. 4, p. 06-14, 2003.

MOCELIN, D. G. Concorrência e alianças entre pesquisadores: reflexões acerca da expansão de grupos de pesquisa dos anos 1990 aos 2000 no Brasil. Revista Brasileira de Pós-Graduação - RBPG, Brasília, v. 6, n. 11, p. 35 64. 2009.

NONAKA, I; TAKEUCHI, H. Criação de conhecimentos na empresa: como as empresas japonesas geram a dinâmica da inovação. Rio de Janeiro: Campus. 1997.

PINHO, J. A. Apresentação - Editorial de abertura do n.47. Organizações \& Sociedade, Salvador, v. 15, n. 47, p. 9-10, 2008.

POLANYI, M. The tacit dimension. London: Routledge e Kegan Paul, 1966.

POWELL, W. W. Learning from collaboration: knowledge and networks in the biotechnology and pharmaceutical industries. California Management Review, Berkeley, v. 40, p. 228-240, 1998.

PROBST, G; RAUB, S.; ROMHARDT, K. Gestão do conhecimento: os elementos construtivos do sucesso. Porto Alegre: Bookman, 2002.

SOUZA, E. P.; PAULA, M. C. S. Qualis. InfoCAPES - Boletim

Informativo da CAPES. Brasília, v.10, n. 2, p. 06-24, abr/jun., 2002. 